Schulich School of Law, Dalhousie University

Schulich Law Scholars

Toward a Principled Design of Provincial Cap \& Trade Systems:

Lessons from Nova Scotia's Proposal to Meet the Carbon Pricing Requirement in the Pan-Canadian Framework for Climate Change

Meinhard Doelle

Follow this and additional works at: https://digitalcommons.schulichlaw.dal.ca/scholarly_works

Part of the Environmental Law Commons 


\title{
Toward a Principled Design of Provincial Cap \& Trade Systems: Lessons from Nova Scotia's Proposal to Meet the Carbon Pricing Requirement in the Pan- Canadian Framework for Climate Change
}

\author{
Meinhard Doelle ${ }^{1}$
}

\section{Introduction}

This article explores the Cap \& Trade System (C \& T system) proposed by the province of Nova Scotia in response to the call in the Pan-Canadian Framework on Clean Growth and Climate Change for all provinces to implement a carbon pricing mechanism. ${ }^{2}$ The proposed $\mathrm{C} \& \mathrm{~T}$ system itself and the way it has been developed offers insights into two ongoing debates in the governance of climate mitigation. The first debate is about the strength and weaknesses of various carbon pricing mechanisms, most notably the carbon tax and cap and trade systems. ${ }^{3}$ The second debate is about the relative importance of carbon pricing and other efforts to reduce emissions, sometimes referred to as "complementary" measures. ${ }^{4}$

To offer context for this analysis, this article will first describe the history of climate mitigation efforts in Nova Scotia, and place the current debate about Nova Scotia's C \& T system in the context of the 2015 Paris Climate Agreement ${ }^{5}$ and the 2016 PanCanadian Framework on Climate Change. ${ }^{6}$

\section{The Context: Paris, the Pan Canadian Framework \& Mitigation History in NS}

It is important to view Nova Scotia's contribution to the national climate mitigation effort in the context of the global effort to address climate change. The Paris Climate Agreement was concluded in Paris in December, 2015, was ratified by Canada in short order, and came into force in November, 2016. ${ }^{7}$ It commits the global community to

\footnotetext{
${ }^{1}$ Professor of Law, Schulich School of Law, Marine \& Environmental Law Institute, Dalhousie University. I would like to thank Kate Ervine, Andrew Green, and Stephen Thomas for their helpful comments on earlier drafts of the paper, and JD candidate Fabian Suárez-Amaya for his invaluable research assistance.

${ }^{2}$ Government of Nova Scotia, Nova Scotia Cap and Trade Program Design Options (Halifax: Government of Nova Scotia, 2017) [Program Design Options].

${ }^{3}$ Lawrence Goulder \& Andrew Schein, "Carbon Taxes vs. Cap and Trade: A Critical Review” (2013) 4:3 Climate Change Economics 1; Shi-Ling Hsu, The Case for a Carbon Tax: Getting Past Our Hang-Ups to Effective Climate Policy (Washington, DC: Island Press, 2011); Kathryn Harrison, “A Tale of Two Taxes: The Fate of Environmental Tax Reform in Canada" (2012) 29:3 Rev Pol'y Research 383.

${ }^{4}$ Ekaterina Rhodes \& Mark Jaccard, "A Tale of Two Climate Policies: Political Economy of British Columbia's Carbon Tax and Clean Electricity Standard” (2013) 39:2 Can Pub Pol'y S37 [Rhodes].

${ }^{5}$ The Paris Agreement, 12 December 2015, C.N.63.2016.TREATIES-XXVII.7.d, (entered into force 4 November 2016) online: <https:/unfccc.int/resource/docs/2015/cop21/eng/109r01.pdf>.

${ }^{6}$ Government of Canada, The Pan-Canadian Framework on Clean Growth and Climate Change (Ottawa: Government of Canada, 2016) online:

$<$ https://www.canada.ca/en/services/environment/weather/climatechange/pan-canadian-framework.html $>$

${ }^{7}$ United Nations Framework Convention on Climate Change, Paris Agreement: Status of Ratifications, (New York: United Nations, 2017) online: <http://unfccc.int/paris_agreement/items/9444.php>.
} 
keeping global temperature increases to well below 2 degrees while making efforts to keep them to 1.5 degrees. It does this by mandating all member States to set nationally determined mitigation, adaptation and finance contributions that will be subject to 5-year review cycles for global adequacy along with a commitment from States to increase their ambition over time. ${ }^{8}$ Canada's nationally determined contribution was set by the previous government at $17 \%$ below 2005 levels for 2020 and $30 \%$ for 2030 . $^{9}$

In return for having control over national commitments, States agreed that those commitments serve as a floor rather than as a ceiling of their efforts. The 2020 and 2030 commitments put forward by Parties were assessed by UNEP in the lead up to Paris, and were found collectively to be inadequate by around 15 GT by 2030 . This significant gap was formally acknowledged in Paris. ${ }^{10}$ Parties are expected to make up this gap by increasing their 2020 and 2030 contributions beyond their current nationally determined contributions. What this means for Canada is that it has in fact committed to do more than meet its current 2020 and 2030 targets. Given that Canada has done less than most developed countries to date, has relatively high historic emissions, and more capacity to act than developing countries, the global community is expecting Canada to make a significant contribution to closing this gap. ${ }^{11}$

As a first step toward meeting its current commitments, Canada started to negotiate an implementation agreement with the provinces almost immediately upon returning from Paris. In the fall of 2016, the federal government announced its Pan-Canadian Framework on Climate Change, a plan that begins to implement Canada's commitments under the 2015 Paris Climate Agreement. The framework was supported by most provinces including Nova Scotia. Nova Scotia supported it upon its release, after having only weeks earlier walked out of the negotiations over objections to the carbon pricing requirement.

The Pan-Canadian Framework includes three key elements, a carbon price, an agreement to phase out the use of coal for electricity generation, and the announcement of complementary measures. The carbon price will take different forms in different provinces, as will complementary measures, which will constitute a combination of some national efforts and more tailored efforts in each of the provinces. The phase out of coal is set for 2030, but Nova Scotia is expected to negotiate an equivalency agreement on coal that will allow it to use some coal after 2030 to back up its wind and other intermittent sources of power. ${ }^{12}$

The carbon price turned out to be the most controversial element of the Pan-Canadian Framework. The federal government announced its intention to implement the carbon

\footnotetext{
${ }^{8}$ Daniel Klein et al, The Paris Climate Agreement on Climate Change: Analysis and Commentary, (Oxford University Press) [forthcoming in 2017].

${ }^{9}$ Government of Canada, Canada's 2017 Nationally Determined Contribution Submission to the United Nations Framework Convention On Climate Change, (Ottawa: Government of Canada, 2017) online: $<$ http://www4.unfccc.int/ndcregistry/PublishedDocuments/Canada\%20First/Canada\%20First $\% 20 \mathrm{NDC}$ Revised\%20submission\%202017-05-11.pdf>.

${ }^{10}$ M. Doelle, “The Paris Agreement, Historic Breakthrough or High Stakes Experiment?” (2016) 6 Climate Law 1.

${ }^{11}$ Climate Action Tracker, Assessment of Canada's Nationally Determined Contribution (Climate Action Tracker, 2017) online: <http://climateactiontracker.org/countries/canada.html $>$.

${ }^{12}$ Program Design Options, supra note 2 at 4.
} 
price over the objection of dissenting provinces, such as Saskatchewan, essentially by imposing a federal carbon price and returning the revenues generated to the province in some form. A discussion paper on the federal backstop carbon price has since been released. ${ }^{13}$ The federal backstop proposal includes two key elements. The first element is a levy on fossil fuel sold in the province. The levy will be based on a carbon tax of $\$ 10$ in 2018 , increasing to $\$ 50$ by 2022 . The second element consists of measures to price emissions from industry. Industrial facilities will be granted free allocations based on the emissions reductions they are expected to achieve, and will only have to pay for emissions above the allocation. ${ }^{14}$ No decision has been made on how revenues generated from the fossil fuel levy are to be returned to the province. Most provinces are expected to design or already have their own carbon pricing mechanism. ${ }^{15}$

It is important to consider Nova Scotia's commitments under the framework in light of what it has already achieved. Nova Scotia has, in the past decade, moved from a climate mitigation laggard to a leader in emission reductions in the electricity sector, while making some progress in other areas. ${ }^{16}$ Historically, about $80 \%$ of Nova Scotia's electricity was produced using coal, about $10 \%$ oil and $10 \%$ small scale hydro. As a result, electricity accounted for about half of Nova Scotia's GHG emissions. Emissions from other sources, including transportation, buildings, industrial processes, agriculture, and forestry were fairly typical for a relatively rural province with largely resource based industries. Until 2005, Nova Scotia had made no significant efforts to reduce its emissions.

In 2005, Nova Scotia began to take serious steps to curb its GHG emissions from electricity. These initial efforts were codified in 2007 in the Environmental Goals and Sustainable Prosperity Act (EGSPA) and further enhanced in Nova Scotia's 2009 Climate Action Plan. ${ }^{17}$ Further improvements to Nova Scotia's emission reduction efforts have been made since. Nova Scotia was the first province to impose binding emission reduction targets on the electricity sector, and it imposed reasonably aggressive renewable energy targets for 2015 and 2020. It has also become a leader in conservation

\footnotetext{
${ }^{13}$ Environment and Climate Change Canada, Technical Paper On The Federal Carbon Pricing Backstop (Gatineau: Government of Canada, 2017) online:

$<$ https://www.canada.ca/content/dam/eccc/documents/pdf/20170518-2-en.pdf $>$.

${ }^{14}$ A free allocation means that the right to emit up to the limit set in the cap and trade system is allocated at no charge to emitting facilities rather than distributed by auction or at a set price per ton of emission. What each covered sector is expected to achieve is to be based on some notion of a yet to be determined 'best in class' comparison.

${ }^{15} \mathrm{BC}$, Alberta, Ontario and Quebec have their pricing mechanisms well established. Most other provinces have indicated that they intend to implement their own pricing mechanism rather than rely on the federal backstop. John Paul Tasker, "Here's Where the Provinces Stand on Carbon Prices" CBC (03 October 2016), online: <http://www.cbc.ca/news/politics/provinces-with-carbon-pricing-1.3789174>.

${ }^{16}$ Some measures, such as improving the energy efficiency of new buildings and of cars, have been developed under Nova Scotia's Environmental Goals and Sustainable Prosperity Act. The most significant impact has been in the building sector. Limited progress has been made with respect to transportation, forestry, agriculture and industrial emissions. Moat of these efforts were tracked under the Environmental Goals and Sustainable Prosperity Act, SNS 2007, c 7 [EGSPA].

${ }^{17}$ EGSPA supra note 16; see also: Nova Scotia Department of Environment, Toward a Greener Future: Nova Scotia's Climate Change Action Plan (Halifax: Government of Nova Scotia, 2009) online: $<$ https://climatechange.novascotia.ca/sites/default/files/uploads/ccap.pdf $>$.
} 
and efficiency in the electricity sector, largely through the creation of an independent efficiency agency in the form of Efficiency One. ${ }^{18}$

By the time the Pan Canadian Framework was announced in 2016, Nova Scotia had reached its target of $25 \%$ renewable energy target for 2015, and was well on its way to reach its 2020 target of $40 \%$. Its binding emission reduction and efficiency targets for 2020 were also well within reach. Nova Scotia had also joined the New England Governors and Eastern Premiers in announcing 2030 emission reduction targets of 3545\% below 1990 levels for 2030. With power from Muskrat Falls, tidal, wind, and solar, and the experience gained in integrating intermittent renewables into the electricity grid, the 2030 target also seems well within reach. In fact, subject to the future of proposed and approved LNG facilities in the province, there is every expectation that NS will be able to surpass its 2030 target in light of the ongoing efforts in the electricity sector.

Outside the electricity sector, progress has been modest. Through EGSPA, Nova Scotia has implemented improved efficiency standards for new buildings, ${ }^{19}$ and has kept up with other jurisdictions on fuel efficiency standards for new vehicles. ${ }^{20}$ No targets have been set for other sectors. No policies are in place to encourage the electrification of transportation and heating. No regulatory action has been taken to deal with emissions from industries, agriculture, and forestry.

The Pan Canadian Framework recognizes Nova Scotia's past efforts to reduce emissions from the electricity sector, and it offers Nova Scotia considerable flexibility going forward. This flexibility can be used to further accelerate progress, but this is by no means guaranteed in light of commitments to date. Much will depend on how key elements, such as the equivalency agreement on coal and the Cap and Trade system, are implemented, and whether they are supported by further regulatory action and incentives to complete transition from fossil fuels to renewables. The role of the proposed $\mathrm{C} \& \mathrm{~T}$ system in accelerating the transition toward GHG emission neutrality is considered below.

\section{The Proposed NS C \& T System}

The government of Nova Scotia released a discussion paper on its proposed Cap and Trade (C \& T) System for provincial GHG emission reductions in the spring of $2017 .{ }^{21}$ The discussion paper outlines the key design elements of the proposed C\&T system. As discussed below, it is largely designed to meet the minimum requirements of the carbon pricing mechanisms set out in the Pan-Canadian framework while minimizing the impact on covered sectors. As currently proposed, it will have limited impact on GHG emissions in Nova Scotia.

\footnotetext{
${ }^{18}$ Efficiency One, 2016 Annual Report (Halifax: Efficiency One, 2016); Brendan Haley, Energy Cost Politics and the Environment in Nova Scotia (Halifax: Canadian Centre for Policy Alternatives, 2010); see also EGSPA, supra note 16 ss 3(2)(g), 4(2)(a)(i), 4(2)(c), 5(b), 7(1)(c).

${ }^{19}$ EGSPA, supra note 16 ss 4(2)(c)-(d), 4(2)(r).

${ }^{20} \mathrm{Ibid}, \mathrm{s} 4(2)(\mathrm{e})$.

${ }^{21}$ Program Design Options, supra note 2.
} 
C \& T systems work by setting limits on facilities collectively rather than individually and allowing trading between facilities to encourage emissions to happen where they are least expensive. The basic elements of the system are the overall limit for facilities that are included in the system (the overall cap for captured facilities), a distribution of the right to emit up to the limit (allocation), and the right of captured facilities to trade allocations. Captured facilities are facilities which will be included under the C \& T System.

Prospective captured actors under the Nova Scotian system include suppliers of fossil fuels, the electricity sector, and large industrial emitters with emissions above 100,000 tons per year. The system is expected to capture less than 20 different actors, made up of suppliers of transportation and heating fuel in the province, Nova Scotia Power, and a few very large industrial emitters. The focus on upstream facilities reduces the administrative cost of the system, but also limits the number of emission reduction options likely to be motivated through its implementation. ${ }^{22}$

Fuel suppliers, for example, will not be motivated to encourage any reduction in the consumption of the products they sell, and can in fact be expected to do everything within their power to prevent their customers from taking action to reduce consumption of their product. They can be expected to purchase the cheapest credits available, and may or may not pass on some of the cost to their consumers, depending on market conditions and regulations. ${ }^{23}$

Both combustion and process emissions from captured facilities are covered, but fugitive emissions are not. ${ }^{24}$ Methane emissions from leaks in natural gas pipelines, for example, would not be captured. The system is expected to capture about $90 \%$ of emissions in Nova Scotia, excluding most notably fugitive methane emissions from agriculture and oil and gas operations. Non-covered sectors, such as agriculture and forestry, cannot participate voluntarily, but will be permitted to sell offset credits into the cap and trade system. Protocols for the certification of credits from these sectors are to be approved (if suitable protocols are found to exist) or developed by the province.

A key outstanding issue is the allocation of proportions of the cap to captured facilities. The province has yet to finalize the caps to be set for each of the sectors or actors. The sector caps are to be negotiated with Environment Canada based on modeling of the emission reductions expected in each covered sector from a carbon price of $\$ 10$ in 2018 increasing to $\$ 50$ by 2022. For Nova Scotia Power, the cap is to be pre-set at the

\footnotetext{
${ }^{22}$ Upstream facilities are large facilities that produce products that result in emissions. Downstream facilities tend to be smaller facilities closer to the end user of the product. In the oil sectors, the oil sands would be an upstream facility, whereas the local gas station would be a downstream facility.

${ }^{23}$ The price of gasoline, for example, is regulated by the NS Utility and Review Board. See Petroleum Products Pricing Regulations, NS Reg 286/2009, s 16(1).

${ }^{24}$ Fugitive emissions refer to emissions resulting from the emission of greenhouse gases other than from the combustion of fossil fuels. The most common fugitive emission is the release of methane from natural gas and agricultural operations.
} 
emission reductions the utility will achieve under current regulatory requirements to reduce GHG emissions and its legislated renewable energy targets. ${ }^{25}$

Once the cap for each covered sector is settled with Environment Canada, the province will have its overall cap for each of the first 5 years of the operation of the cap and trade system. It will then decide how much of the overall cap it will allocate to each sector or facility. The province has not committed to any particular methodology for this allocation, ${ }^{26}$ but has indicated that it intends to allocate emission permits for free rather than to auction them, ${ }^{27}$ as is the case in Ontario. ${ }^{28}$ Assuming the overall caps negotiated with Environment Canada provide for meaningful emission reductions in the first 5 years, the allocation to captured facilities will be important, as it will determine what share of emissions from each facility or operation are free. For example, an allocation based on historical emissions would tend to favour heating oil over natural gas, as the latter is relatively new in the province and its market share is still small. If the province intends to encourage fuel switching from oil to natural gas and electricity, allocation based on historical emissions would not be appropriate. ${ }^{29}$ Similar issues arise with transportation.

The C \& T system will allocate caps and credits annually. To provide flexibility to captured facilities, the system will have three-year compliance periods. The system will allow banking of extra credits for future compliance periods, but borrowing from future compliance periods is not contemplated. The three-year compliance periods and banking will allow facilities some opportunity to adjust to unexpected increases in emissions. This flexibility will be critical, as the system is not intended to be linked with $\mathrm{C} \& \mathrm{~T}$ systems in other provinces, at least not initially. ${ }^{30}$

It is important to point out, in this regard, that the system will have important design features that are different from the system being implemented in Ontario and Quebec, both of which are based on and either already linked or to be linked with the Western

\footnotetext{
${ }^{25}$ Based on stakeholder consultations held by the province of Nova Scotia on its proposed C \& T system in March, 2017.

${ }^{26}$ Potential principles for allocation include $\%$ of historic emission, output based allocations, or some fixed sector based benchmarks. Allocation based on which sectors should be supported, and which sectors should be pushed harder to reduce emissions can also factor into allocation decisions.

${ }^{27}$ Program Design Options, supra note 2 at 13.

${ }^{28}$ The Ontario system offers free allocation for industrial emitters, but fuel suppliers/distributors, electricity importers, and some electricity generators must purchase allowances. See: Government of Ontario, Cap and Trade: Program Overview (Toronto: Government of Ontario, 2016) online:

$<$ https://www.ontario.ca/page/cap-and-trade-program-overview\#section-2>; see also Greg Hunter with the collaboration of Peter Harrison, An Assessment of the Fiscal Impact of Cap and Trade (Toronto: Fiscal Accountability Office of Ontario, 2016) at 11.

${ }^{29}$ Andrew Leach et al, Climate Leadership: Report to the Minister (Edmonton: Government of Alberta, 2015); Guy Meunier, Jean-Pierre Ponssard \& Philippe Quirion, "Carbon Leakage and Capacity-based Allocations: Is the EU Right?” (2014) 68:2 J Env Economics \& Management 262; Richard Munson \& Thomas R Kasten, "Simplifying Climate Change Legislation: Output-based Allocations" (2008) 21:5 Electricity J 64.

${ }^{30}$ Linking refers to the ability of captured facilities to buy and sell credits to and from facilities captured by systems in other jurisdictions. Regarding Nova Scotia's intention not to link, see: Program Design Options, supra note 2 at 5.
} 
Climate Initiative. ${ }^{31}$ For example, the threshold for industrial facilities for jurisdictions who are part of the Western Climate Initiative is 25,000 tons, compared to 100,000 tons in Nova Scotia. ${ }^{32}$ The design differences may make it more difficult to link to these jurisdictions in the future.

\section{Assessment of NS's Proposed C \& T System}

A complete assessment of the proposed $\mathrm{C} \& \mathrm{~T}$ system is not possible until the overall cap for Nova Scotia is negotiated with Environment Canada, the allocation to captured facilities is finalized, and the protocols for agriculture and forestry are announced. There are, however, elements of the proposed system that give rise to concerns about its effectiveness.

The free allocation of allowances to all facilities is perhaps the most serious shortcoming of the proposed system. Free allocation risks offering a windfall to captured facilities and may reduce the financial incentive to reduce emissions. It may also reduce the price signal that will be passed down from the captured upstream actors to consumer, reducing the financial incentive of consumers to make choices that reduce emissions. It may furthermore hinder the entry into the market by competitors, potentially reducing economic prosperity. Most importantly, free allocation means there are no additional revenues available to improve the effectiveness and fairness of the overall effort to reduce GHG emission in Nova Scotia through the implementation of complementary measures, and to support economic development associated with the transition.

The second major concern with the proposed $\mathrm{C} \& \mathrm{~T}$ system is that it appears that there will be three sources of GHG emission reduction credits that have the potential to flood the system with cheap credits, eliminating any incentive for the fundamental transition that needs to happen, particularly in the transportation and building sectors. One potentially significant source of cheap credits is Nova Scotia Power. The cap on the electricity sector is based on current regulatory requirements. It seems clear that more can be done in this sector, likely at a more reasonable cost than other covered sectors. It seems likely that Nova Scotia Power will have surplus credits to sell, potentially at a large scale. Agriculture and forestry are the other two sources of potentially large volumes of cheap offset credits. Depending on the protocols that will be adopted, both have the potential to sell significant credits into the system. Unless stringent protocols are negotiated, it is reasonable to expect that these offset credits will be cheap, and a

\footnotetext{
${ }^{31}$ Ontario will link with Quebec and California in 2018. See Climate Change Mitigation and Low-carbon Economy Act, SO 2016 c 7 s 76(1) online: <https://www.ontario.ca/laws/statute/16c07>; see also: Tamsin McMahon, "California, Quebec and Ontario push forward with cap-and-trade program" The Globe and Mail (20 April 2017), online: $<$ https://www.theglobeandmail.com/news/world/california-quebec-and-ontario-pushforward-with-cap-and-trade-program/article34770662/>.

${ }^{32}$ Western Climate Initiative, Design for the WCI Regional Program (Western Climate Initiative, 2010) at DD-12 online: $<$ http://www.westernclimateinitiative.org/the-wci-cap-and-trade-program/program-design>.
} 
portion of the credits will be granted for business as usual emission reduction efforts. ${ }^{33}$ This certainly has been the experience elsewhere, including with respect to the Clean Development Mechanism under the Kyoto Protocol. ${ }^{34}$

The focus of the system on a few upstream actors, while administratively efficient, does have significant implications for the proposed C \& T system, particularly in combination with the decision not to link to other jurisdictions. On its face, this approach could create challenges for new industrial actors. In the absence of another solution in the discussion paper, it is difficult to avoid the conclusion that this problem will be addressed by designing the system to be sufficiently lax that it can accommodate new emitters without penalizing them so heavily that they are discouraged from coming to Nova Scotia.

Space for new entrance could be secured through a combination of generous overall caps and generous protocols for forestry and agriculture, resulting in an abundant supply of cheap credits. If this does not happen, new industries with significant emissions will likely be deterred from locating in Nova Scotia. ${ }^{35}$ Of course, linking to other systems or a carbon tax in place of the $\mathrm{C} \& \mathrm{~T}$ system would be effective ways of addressing this problem without undermining the environmental objective.

The focus on a few upstream actors also reduces the opportunity to motivate downstream actors to take measures to reduce emissions. Fuel suppliers will not be motivated to take measures to reduce the consumption of fossil fuels, thought some downstream price impact would be expected. Imposing a cap on fuel suppliers will encourage them to buy cheap credits and minimize the impact of the $C \& \mathrm{~T}$ system on their customers.

\section{Key Debates on Climate Mitigation Governance}

It is important to consider the proposed NS C \& T system in the context of the broader debates about effective carbon pricing and its role in the regulation of GHG emissions. These debates are ongoing both in Canada and in other jurisdictions. There are two key elements to this debate. One is the debate about the most effective carbon pricing mechanism, a debate that has focused largely on C \& T systems and carbon taxes. ${ }^{36}$ The

\footnotetext{
${ }^{33}$ Any offset credits inflate the overall cap of the system. Difficulties in separating business as usual emission reductions from additional emission reductions in offset sectors undermine the environmental goals of the system. Jonathan L. Ramseur, The Role of Offsets in a Greenhouse Gas Emissions Cap-andTrade Program: Potential Benefits and Concerns (Washington, DC: Congressional Research Library, 2009).

${ }^{34}$ Martin Cames et al, How Additional is the Clean Development Mechanism? (Berlin: Institute for Applied Ecology, 2016) online:

$<$ https://ec.europa.eu/clima/sites/clima/files/ets/docs/clean dev mechanism en.pdf $>$. Of course, there has been work done through post-Kyoto mechanisms on improving how offsets are created and accounted for.

${ }^{35}$ This aspect of the system is likely to be supported by existing facilities in NS, as it will protect them from competition.

${ }^{36}$ David Driesen, "Emissions Trading Versus Pollution Taxes: Playing "Nice" With Other Instruments" (2017) Environmental Law [forthcoming]; Goulder, supra note 3; Hsu, supra note 3; Harrison, supra note 3.
} 
second element is the debate about the relative contribution or appropriate combination of carbon pricing and complementary measures. ${ }^{37}$

An emerging part of this debate is the compatibility of carbon pricing with some other measures. For example, as Driesen points out, a cap and trade system that offers generous allocations to coal burning power plants followed by a decision to phase out coal can lead to undesired consequences that undermine the economic and environmental benefits of the subsequent coal phase out. ${ }^{38}$ Essentially, the phase out of coal would leave the owners of the coal plants with allocations they can sell at a profit into the system, resulting in a disincentive for other captured facilities to reduce their own emissions.

The debate over C \& T versus carbon taxes was initially a debate around the control of the price versus control over the environmental goal in the form of the overall cap on emissions. Those advocating for a carbon tax tended to be concerned about the economic impact of setting a limit on emissions without knowing the cost of meeting those limits. Those advocating for a $\mathrm{C} \& \mathrm{~T}$ system over a carbon tax tended to be concerned that the environmental benefits that could be achieved with a given carbon price was difficult to predict with any accuracy. A C \& T system was considered to offer more predictable environmental benefits. ${ }^{39}$

A number of things have changed in this debate in recent years. First, in the context of GHG emissions, the cost of mitigation is much better understood, meaning that it is much easier to estimate the cost of meeting a certain emissions cap. We also are better able to estimate the emission reductions that can be achieved with a given price on carbon, making it easier to estimate the environmental impact of a given carbon tax. ${ }^{40}$

Furthermore, and perhaps most importantly, the design of carbon taxes and $\mathrm{C} \& \mathrm{~T}$ systems have become much more nuanced over time, resulting in the blurring of the lines between carbon taxes and $\mathrm{C} \& \mathrm{~T}$ systems. By setting minimum and maximum prices in a $\mathrm{C} \& \mathrm{~T}$ system, for example, a well-designed cap and trade system can function more like a carbon tax, both in terms of offering price certainty and in terms of creating uncertainty in the environmental benefits achieved.

\footnotetext{
${ }^{37}$ Mark Jaccard, Mikela Hein \& Tiffany Vass, Is Win-Win Possible: Can Canada's Government Achieve Its Paris Commitment . . a and Get Re-Elected? (Vancouver: School of Resource and Environmental Management at Simon Fraser University, 2016); Tiffany Vass, Trading Off Political Acceptability and Economic Efficiency: Policy Options for Reducing Canada's Electricity and Transportation Emissions, (MRM Thesis, Simon Fraser University, 2016); see also: Rhodes, supra note 4.

${ }^{38}$ Driesen, supra note 36.

${ }^{39}$ Nicholas Rivers \& Mark Jaccard, "Intensity-Based Climate Change Policies in Canada" (2010) 36:4 Can Pub Pol'y 409 at 411-413; see also: Harrison, supra note 3; David Houle, Carbon Pricing in Canadian Provinces: from Early Experiments to Adoption (1995-2014) (Ph. D. Thesis, University of Toronto, 2015) at 25,33 .

${ }^{40}$ Stewart Elgie \& Jessica McClay, "BC's Carbon Tax Shift Is Working Well after Four Years ('Attention Ottawa')" (2013) 39:2 Supp Can Pub Pol'y S1 [Elgie].
} 
The more general debate over the role of carbon pricing in climate mitigation centers around a few key elements. One area of divergence is about the relative value of carbon pricing. The main value of carbon pricing is that it tends to reduce the cost of mitigation. However, this comes at the cost of losing control over where the emission reductions take place. The value of more directed measures is that they ensure that mitigation efforts happen where there are opportunities to take advantage of co-benefits and for integrated solutions that address climate change without creating other sustainability challenges. At the heart of the debate is whether the priority is to reduce emissions at the lowest cost, or whether it is more important to control where the emission reductions are achieved, so that there are opportunities to maximize collateral economic, social and environmental benefits and minimize negative consequences of specific emission reduction measures.

Another, related area of debate is about the need for and value of measures to complement carbon pricing. There is a general recognition that in order for carbon pricing to be effective, societal actors must have alternatives to their current behaviour. Different views on the role of governments to create such alternatives are often underlying debates about the role of complementary measures to support carbon pricing in achieving emission reductions. Should governments invest in specific alternatives or should this be left to the private sector? ${ }^{41}$ Should governments regulate the elimination of some options, or should this be left to be worked out through the carbon pricing mechanism? $?^{42}$

An example where these issues are playing out is in the transportation sector. The role of government in developing infrastructure for public transportation, active transportation and the electrification of vehicular transportation are among the issues to be resolved. How these issues are resolved will determine the relative role of carbon pricing versus complementary measures in facilitating the transition of the transportation sector to GHG neutrality. Will the transition to electric vehicles happen without government investment in charging stations and subsidies for the purchase of electric cars? What government measures are needed to ensure that active and public transportation will be viable options for individuals facing the higher cost of gasoline as a result of a carbon price?

The proposed NS C \& T System's environmental integrity in terms of GHG emission reductions will largely hinge on the limits being negotiated with Environment Canada and the protocols to be adopted for offsets from agriculture and forestry. The broader integrity of the proposed system, in terms of its ability to facilitate an overall transition to GHG neutrality in a manner that is equitable, particularly to vulnerable populations, is very much an open question. The answer depends largely on appropriate complementary measures to ensure the broader goals beyond low cost short-term emission reductions are met.

It seems clear that in the transportation sector, the proposed system will do little more than result in a marginal increase in the price of gasoline. This may encourage some

\footnotetext{
${ }^{41}$ Zachary D. Liscow \& Quentin C. Karpilow, "Innovation Snowballing and Climate Law” (2017) online:

Yale Law \& Economics Research Paper No. $571<$ https://ssrn.com/abstract=2927441>.

${ }^{42}$ Rhodes, supra note 4; Driesen, supra note 36; Jaccard, supra note 37.
} 
Nova Scotians to drive less, but without significant efforts to enhance public and active transportation alternatives, many Nova Scotians, especially in rural parts of the province, will have little choice but to keep driving. Without investment in charging stations and some financial support for the purchase of electric vehicles, the only reasonable transportation option for most Nova Scotians will remain the gasoline car. This is particularly important from an equity perspective, as rural residents will not have access to effective public transportation options. Reductions from the $\mathrm{C} \& \mathrm{~T}$ system alone will be marginal and, most importantly, will not be transformational or equitable.

Similar challenges exist in the building sector, where the proposed C \& T system alone will do little to transform the build environment to more sustainable, GHG emission neutral sources of heating and cooling, and more energy efficient construction. An increase in the cost of fossil fuel based energy will be helpful, but much more needs to be done to make this transition. For example, decisions about the effort and investment into the energy efficiency of a new building and its sources of energy are often made by builders who don't bear the cost of operation and maintenance, including the cost of fuel or of future building upgrades. This and similar disconnects between the price signal of even an effective carbon price threatens to undermine the price incentive of the carbon price in encouraging better building design. Well designed and implemented complementary measures will be critical to achieving the transition to GHG emission neutrality in the building sector. ${ }^{43}$

The proposed $\mathrm{C} \& \mathrm{~T}$ system serves to highlight a few of the limitations of carbon pricing, and the risks associated with choosing a $\mathrm{C} \& \mathrm{~T}$ system as the pricing mechanism. Nova Scotia has achieved progress in the electricity sector using regulatory approaches, so far without a carbon price. In some of the key sectors, such as buildings and transportation, the price signal alone will not be enough to facilitate the further transition that is clearly needed. Finally, the proposed C \& T system illustrates the challenge of designing a principled pricing mechanism in a political context where the driving forces are not the effectiveness of the mechanism but the economic impact it will have on powerful economic actors. The next section explores what a principled design of a cap and trade system might take into account. This is done in an effort to illustrate the hidden choices in the design proposed by the province of Nova Scotia.

\section{Principled System Design}

One of the challenges of implementing a $\mathrm{C} \& \mathrm{~T}$ system is that it will affect a wide range of actors, and if it is going to have an impact in facilitating a transition of the scale required to address climate change, it must affect some powerful actors significantly. As a result, any carbon pricing mechanism designed by any government will be subject to political pressures from powerful actors.

\footnotetext{
${ }^{43}$ Rhodes, supra note 4.
} 
A particular challenge in this regard is that it is often the most powerful actors that have to be most challenged to change, while the sectors that stand to benefit economically from the transition are often still emerging and therefore tend to have less power and influence. In this context, the best hope of designing an effective $\mathrm{C} \& \mathrm{~T}$ system is a principled and transparent approach. The C \& T system's design must be founded on fundamental principles that ensure we act in the best interest of society as a whole rather than in the interest of the status quo or in the interest of selected powerful actors. This section explores some principles that might guide the design of an effective carbon pricing mechanism.

A key element of a principled approach would be not to treat all sectors of the economy the same when designing the system. By recognising differences, it is then possible to base key design choices, such as the manner of allocation, the volume of allowances, and the transition from short, to medium to long term, on principles that enhance the effectiveness of the system rather than on political power and influence. Among the principled design questions are the following:

- How significant is the cost of the carbon pricing mechanism in the overall cost of the product or service being provided by the sector?

- Is the sector likely to pass on the cost of the carbon pricing mechanism, thus passing on the impact to the user of the product or service?

- Is the sector likely to internalize the cost of the carbon pricing mechanism, thus reducing the profitability of the sector?

- How important is the sector in terms of employment?

- How important is the sector in terms of government revenues from taxes and royalties?

- Does the sector have opportunities to thrive and grow through the transition to GHG neutrality?

- Is the sector likely to be part of a GHG emission neutral economy?

- Does the sector provide an essential product or service?

- Is the sector vulnerable to competition from abroad (either in the domestic market or export market)?

- How significant is the cost of supporting or favouring this sector, compared with other sectors considered in the system?

- What are the equity considerations of this sector being changed or affected by the system?

Under a principled approach proposed here, these design questions would be asked for each of the key sectors in Nova Scotia, including electricity, the fossil fuel sector, transportation, buildings, manufacturing, mining, agriculture, forestry, and fisheries. This type of analysis would allow for a design that is informed by an understanding of which sectors are legitimately trade-exposed, which sectors will pass on the carbon price to users, which sectors are in need of some protection in the short term, which sectors are worth supporting in the medium term, and which sectors, end users and workers are in need of protection and assistance through the transition to GHG emission neutrality. 
The analysis might start with three categories of sectors. First, there will be sectors, such as the exploration and distribution of fossil fuels, that are important today, but will likely not be part of a GHG neutral future. Second, there are many sectors, such as electricity, buildings, transportation, agriculture, forestry, manufacturing, and mining, that will be part of the GHG neutral economy of the future, but that will have to undergo significant transitions to become carbon neutral. Third, there are sectors, such as renewable energy, green building design, smart grid and energy storage technologies, sustainable agriculture and forestry, and others that have great potential to be a growing part of our economy because they offer solutions to the global challenge of transitioning to GHG neutrality.

Some work has already been done on these issues. A 2015 report of the Ecofiscal Commission, for example, considered how trade-exposed various sectors of Nova Scotia's economy are. ${ }^{44}$ It concluded that only a few are significantly trade exposed. Experience with BC's carbon tax has been invaluable in helping to understand economy wide implications of carbon pricing. ${ }^{45}$ The experience can also help to identify which end users and workers will need protection because the carbon price is passed on to those who would be unfairly affected by it.

The end result of such an approach, based on existing analysis such as the 2015 report of the Ecofiscal Commission, would likely be that most sectors should be included in the $\mathrm{C}$ $\&$ T system (including agriculture, forestry, and fugitive emissions). It would likely conclude that most actors should not be granted free allocations, but should either be auctioned or sold at a fixed price that will increase over time. ${ }^{46}$ It would likely conclude that the very gradual reduction of the caps and the efforts underway in many other jurisdictions in North America and around the world will limit the risk of trade exposure.

The analysis would identify those specific actors that need protection, it would be transparent about the unique circumstances that warrant special treatment and for how long. Furthermore, the analysis would identify the end users and workers in need of protection. The revenues generated from the allocation of allowances would be available to deal with those legitimate equity concerns without giving a free ride to others who either have alternatives or the resources to internalize the cost of the GHG emissions their choices represent.

\footnotetext{
${ }^{44}$ Elizabeth Beale et al, Provincial Carbon Pricing and Competitiveness Pressures: Guidelines for Business and Policymakers (Montréal: Canada's EcoFiscal Commission, 2015).

${ }^{45}$ See especially Brian Murray \& Nicholas Rivers, "British Columbia's revenue-neutral carbon tax: A review of the latest "grand experiment" in environmental policy" (2015) 86 Energy Policy 674; Noel Melton \& Jotham Peters, Is British Columbia's Carbon Tax Good for Household Income? (Vancouver: Navius Research Inc., 2013); see also Elgie supra note 39 at S8.

${ }^{46}$ Of course, there may be other reasons to give free allocations - including a sense of fairness as in the case of NS Power to recognise previous efforts, or to generate political support. Whatever the reason, the number of free permits would likely be eliminated over time, as free allocations are suboptimal. See: Michael J Trebilcock, Dealing with Losers: The Political Economy of Policy Transfers (New York: Oxford University Press, 2014); Jonathan Nash and Richard Revesz, "Grandfathering and Environmental Regulation: The Law and Economics of New Source Review" (2007) 101:4 Northwestern UL Rev 1677; Bruce Huber, "Transitional Policy in Environmental Law" (2011) 35:1 Harv Env LR 91.
} 
A final group of design issues considered here is which sectors should be included in the C \& T system, which should be left out, and which should be permitted to sell offset credits into the system. Under the current proposal, agriculture and forestry would be permitted to sell credits into the system, and fugitive emissions would be excluded from the system. ${ }^{47}$ The main rationale for their exclusion appears to be methodological and administrative challenges associated with their inclusion. Of course, similar challenges exist with the establishment of appropriate protocols to ensure credits have environmental integrity. A key challenge with the consideration of offsets from forestry and agriculture is that there is a significant risk that these sectors will flood the system with large volumes of potentially very cheap credits, thus undermining any incentive for other sectors to reduce emissions. Estimating the volume of credits available from each offset sector and reflecting it in the overall cap would be protect against this risk. In other words, the availability of offsets should result in a reduction of allowances made available through the cap. This approach would reduce concern that the offset protocols could undermine the environmental integrity of the $\mathrm{C} \& \mathrm{~T}$ system. ${ }^{48}$

\section{Conclusion}

The Nova Scotia C \& T System, as proposed, is unlikely to have much, if any impact on either short-term GHG emission reductions in Nova Scotia, or in facilitating a transition to GHG emission neutrality. The large thresholds for industrial facilities will exempt all but a few large facilities. The electricity sector is protected due to past efforts and current regulations. Other actors captured are likely to purchase credits and pass on the cost. ${ }^{49}$ The price of credits is likely to be low, due to cheap credits from the power sectors, agriculture and forestry.

The proposed system is a product of a political process that has resulted in the protection of powerful sectors of the current Nova Scotia economy rather than on a principled design to protect economically important trade-exposed sectors, while pushing the rest of the economy gradually but firmly in the direction of GHG neutrality, protecting only those in need of protection. This article has explored elements of a more principled approach to the design of Nova Scotia's carbon pricing mechanism. It has also highlighted the critical importance of making the carbon pricing mechanism an integral part of an overall strategy for the transition to GHG neutrality.

The Paris Climate Agreement challenges jurisdictions around the world to move from their past tentative steps toward GHG neutrality to designing and implementing a

\footnotetext{
${ }^{47}$ A study of the $\mathrm{BC}$ carbon tax suggests there are few principled reasons to exclude agriculture from carbon pricing. See: Nicholas Rivers \& Brandon Schaufele, "The Effect of Carbon Taxes on Agricultural Trade" (2015) 63 Can J Agricultural Economics 235.

${ }^{48}$ The use of revenues generated to deal with equity issues for vulnerable populations and to further support the transition to GHG neutrality would also have to be addressed.

${ }^{49}$ This certainly has been a key lesson from the experience with the EU emissions trading system. Ref? (re passing on costs) Simon Caney \& Cameron Hepburn, "Carbon Trading: Unethical, Unjust and Ineffective?" (2011) 60:1 Royal Institute Phil Supplement 201 at 225; Dale Beguin et al, The Way Forward for Ontario: Design Principles for Ontario's new Cap-and-Trade System (Montréal: Canada's EcoFiscal Commission, 2015); Leach, supra note 29 at 47.
} 
coherent, comprehensive strategy for this transition. A well-designed carbon pricing mechanism has the potential to be an important part of this overall strategy. That mechanism must have a principled design and effective integration with other measures to ensure the price signal serves to encourage effective, legitimate alternatives. 